\title{
Customer concentration and Profitability in Private HealthCare COMPANIES
}

\author{
Riikka Holopainen \\ University of Eastern Finland \\ Mervi Niskanen \\ University of Eastern Finland \\ Sari Rissanen \\ University of Eastern Finland
}

\begin{abstract}
Previous studies suggest that the customer size and range have implications for the company's performance. In this paper, we investigate the impact of customer concentration on a firm's performance in the framework of healthcare companies. The base of this paper is the questionnaire data of the private Finnish health care companies. We shed light on one corner of diverse and complex combination of the profitability process in the small companies. Thus, we address that the customer, beside other factors, has an influence on a firm's performance. Especially, in small health care companies as most of this research companies are, one or few big customers is a common form of customer base. We found that the customer concentration of the company positively directs the company's performance. Furthermore, some of the contextual factors such as desire to grow contributed to the company's performance too.
\end{abstract}

Keywords: customer concentration, profitability, small and medium-sized enterprise (SME), healthcare business

JEL code: M21, M41

\section{Introduction}

Customer concentration is increasing phenomenon in business. Already, it's effect for the profitability of the company is examined in recent years (Balakrishnan et al. 1996; Campello and Gao 2014; Gosman and Kohlbeck 2009; Gosman's et al. 2004; Huang et al. 2014; Irvine et al 2016; Kelly and Cosman 2000; Kohlbeck 2011; Patatoukas 2012; Snyder 1998). The main research has been done in the manufacturing framework (Becchetti and sierra 2003; Irvine et al. 2016; Patatoukas 2012; Snyder 1998) and in the banking business (Campello and Gao 2014; Kelly and Gosman 2000) leaving the constantly increasing service sector outside of the research. Also, an open empirical question remains as how customer concentration influences on performance within firm. (Bae and Wang 2015; Snyder 1998).

We inspect the phenomena of the customer concentration in the service providers' point of view, not from the client's side. Our aim in this paper is to investigate whether customer concentration has an effect on the performance of the company in the health care industry in Finland. For this reason, we provided a survey of 668 health care firms where we enquired the manager's opinion about the customers, employees, financing, networks, organization structure and competition of the company in 2010. Our research is connected to several shortcomings of earlier literature. First, with this data we bring out some possible factors and their joint effect beside customer concentration which has been raised in the earlier literature (Patatoukas 2012). Secondly, the sample companies are mostly SMEs. Though the average of their sales is 1000 TEUR but they have 9 employees on average. In opposite, the companies in earlier research have been big companies mostly from the COMPUSTAT data (Irvine et al. 2016; Kelly and Gosman 2000; Patatoukas 2012). Further, Patatoukas (2012) expresses the 
problem of many studies using gross margin as a profitability measurement for being too narrow and leaving important costs like advertising and administrative expenses out. Hence, our ratio for the profitability is operating margin $(\mathrm{OM})$ and those fixed costs are excluded from the item.

In the earlier literature, there is a contradictory opinion about the effect of the customer concentration on the company's performance. Patatoukas in his paper (2012), showed that there is a clear positive relation between the customer concentration and the gross margin of the company. He compared the company's profitability and the market stock price differs before and after the reduction of the big customers. Patatoukas (2012) noticed that the stock investors underreacted to the customer concentration changes although the customer concentration observations could give a hint about further performance development. On opposite, Balakrishnan et al. (1996) and Kelly and Cosman (2000) found that the connection of the customer concentration and the profitability is adverse for the company. This supposition got support from the Campello and Gao (2014) when they compared the creditors' opinion for the company's customer concentration. Irvine et al. (2016) evident that the relation of the customer concentration and the company's profitability can have both positive and negative effect. They found that the new companies can suffer for having one or few big customers but the old steady companies can have strong positive impact on customer concentration.

The data of this research consists of health and social companies which are typical service companies. The service sector differs from the manufacturing business for example in cost structure and overall functions. Service as a product is often highly dependent on company's intangible factors as employee's expertise or managements decisions. Further, usually the service can be adapted after demand and cannot be stored, thus it can be compared with highly specialized products. The customer concentration is higher in the industry of the special products or services where the customer base is often narrower. (Contarctor et al. 2003; Raman and Shahrur 2008; Rissanen et al. 2010). In recent years, the number of the health care companies has risen in the countries where those services have previously been mostly publicly provided. (Littunen and Rissanen 2015; Rissanen et al. 2011).

When we inspect the figures that describes the company's main customer's magnitude or the customers that have the purchase agreement from the municipalities, the effect is negative (Kelly and Gosman 2000). This meaning that the one big customer, often the public customer increases the company's uncertainty and degreases the profitability. Similarly, the magnitude of self-payment customers decreases the company's operating margin. These results are as we assumed when modelling our hypothesis. The results of our research shows that the customer base has significant influence on the company's profitability.

This paper proceeds as follows. Section two develops the hypothesis and familiarizes the literature. Section three describes the sample and introduces descriptive statistics. It also includes the model fit and shows the correlation analysis of all variables. Section four describes the multiple linear regression analysis and it also reports the results of the regression. Eventually, section five concludes the research.

\section{Literature review and hypothesis}

There is a contradictory opinion about the effect of the customer concentration on the company's performance in earlier literature. Even in one research, as Patatoukas in his paper (2012) there can be two different results depending on the framework. He showed that there is a clear positive relation between the customer concentration and gross margins of the company and the mean time the same data showed a negative connection between customer 
concentration and operating margins and asset turnover. He compared the company's profitability and the market stock price changes before and after the reduction of the big customers. Patatoukas (2012) noticed that the stock investors underreacted to the customer concentration changes and that the customer concentration observations could give a hint about further performance development. Also, Irvine et al. (2016) evident that the relation of the customer concentration and the company's profitability can be both positive and negative. They found that new companies can suffer for having one or few big customers but the old and steady companies can have a positive impact on customer concentration. The clear negative connection between customer concentration and the performance found researchers as Balakrishnan et al. (1996) and Kelly and Gosman (2000). They state that the strong customer concentration is adverse for the company. This finding gets support from the Campello and Gao (2014). They compared the creditors' opinion for the company's customer concentration and they reveal that the big customer increases the interest rate and the number of restrictive covenants.

Also positive effect can exist and it has reported in cost savings area. Benefits from the customer concentration can exist in gains in lower customer switching costs and lower costs per unit as Kinney and Wempe (2002) and Snyder (1998) argued. However, they reported a negative relationship between customer concentration and cost elasticity, which is metrics of the lower variable-to-fixed costs figures within the warehouse management (JIT) researches. More precisely, the lower cost elasticity, the greater customer concentration (Kinney and Wempe 2002; Snyder 1998). However, a supplier seems to prefer the lasting suppliercustomer relationship rather than decreasing the cooperation (Snyder 1998). Banker et al. (2014) published opposite results. Their analyses showed a negative relationship between demand uncertainty and short-run cost structure like, the more uncertainty among customers, the higher fixed costs and the lower variable costs.

In the earlier research has also observed that the firm's power in networks and its exclusivity strengthen firm's profitability (Galbraith and Stiles 1983) and the same concluded Gosman's et al. (2004) studies when they investigated the capital intangibles and the supplier's major customers. They showed that the customer concentration as an advantage of supply chain arrangement increases operating profitability and further, that the market recognizes this advance. Also, Kohlbeck (2011) researched investor's valuation relationship with retailer's major customer. He revealed that both the large and the smaller supplier advanced for the connection. Further, Huang et al. (2014) inspected the company's tax avoidance against customer concentration and they found that especially governmental major customers provide more stable cash flow, which increase the need for tax avoidance. In Silva's and Santos' (2011) research on company's strategy area has customer concentration identified to be one of several other strategies that maximize profitability and growth. In bankruptcy risk paper (Becchetti and sierra 2003) was customer concentration found to be significant as robust as competitor variables and with better significance than liquidity or profitability as control variables.

The previous discussion suggests that customer concentration effect on company's profitability:

H1: Customer concentration is negatively associated with profitability of the company.

\section{Sample and descriptive statistics}

\section{Method and Variables}

As method in this research, we use multiple regression analysis. It is a suitable method to analyze a group of different factors against one dependent variable if the dependent variable is 
continuous and the independent variables fit into analyze after seven assumptions. These assumptions we test in the latter chapter. Our dependent variable is operating margin and as test variable we apply three customer variables and seven control variables. We have chosen these particular control variables into our model after contingency theory factors. Hence, control variables deal diversely with the area of strategy like desire to grow, environment competitors and co-operation of the company. Among these contextual factors we use the characters of the manager like education, age and gender as control variables.

First, as a dependent variable we apply the operating margin which we have computed in SPSS from the variables EBIT to total sales. By using OM instead of more informative ROE or ROA, we got from the widest sample of the data. Hence, this research concentrate on the firm's short term information without balance sheet effect. The OM tells us the earnings before interest and taxes as well as before adjusted and extraordinary items. Second, we choose three customer base related questions for the independent variable. All these customer variables are continuous and ratios. These explanatory variables are BIGCUS to measure one biggest customer's share, CUSAGR for the service agreement customers' share and CUSSEL for the self-paying customers' share of the company's total sale. More precisely, the measure of the customer concentration is the percentage of the one biggest customer of all the customers (BIGCUS) hence, the bigger this measure is the bigger the concentration of the customers will be. We applied both self-paying customer and service agreement variables both in our analysis because these figures did not come necessarily from the same company.

Eventually, we have several control variables to fulfill the model. Of these variables two first are to measure the strategy of the company, GRDES to measure the desired growth and COMINV to show us if the competition has induced investments. Furthermore, to observe the environment of the company, we choose COOPOT variable. It tells us how much the company have co operations with other companies. Eventually, we include three manager's characteristic control variables in model, MANAGE the age, GENDER the gender and MANED the education level of the manager. (Table 1)

Table 1. Variable definitions

\begin{tabular}{|l|l|}
\hline OM & Absolute value of operating margin, EBIT to sales \\
\hline CUSSEL & Self-paying customers (\%) \\
\hline CUSAGR & Service agreement customers (\%) \\
\hline BIGCUS & One biggest customer (\%) \\
\hline MANAGE & Year of birth \\
\hline EMFUL & Number of Full-time employees \\
\hline EMPAR & Number of Part-time employees \\
\hline EMTOT & Total number of employees \\
\hline SALES & Absolute sales (TEUR) \\
\hline$A S S E T S$ & Absolute total assets (TEUR) \\
\hline EBIT & Absolute value of earnings before interests and taxes (TEUR) \\
\hline GRDES & from 1, no need to grow, to 4, when growth is desired \\
\hline COMINV & from 1, no investments on competition to 5, high investments \\
\hline COOPOT & from 1, no co-operations with other firms to 5, high co-operation \\
\hline$G E N D E R$ & 1 if the manager is female 2, man \\
\hline MANED & from 1, if manager has no vocational education to 5, when university graduate \\
\hline
\end{tabular}




\section{Research design and data}

Our sample is Finnish private health care firms. In 2010, they were in total 17,790 and the questionnaire was sent to 2009 companies of those by choosing the highest growth companies. As we got 668 responses, the response rate was 33\%. Most of the respondents were women $(81 \%)$ and their average age was 51 years. Usually, they had bachelors or master's degree (69\%). The companies were 9 years old, on average and their sales were 1,000.2 TEUR on average. Again, the amount of mean OF total assets was 396.4 TEUR, on average. Most of our sample companies were housing services for elderly and disabled persons $(29 \%)$ and family homes for young people (28\%). Further, third of the companies were in home service business and the remaining $11 \%$ was diverse other companies for example mental health or substance abuse services. The mean value of the employees was 10 of which there were part time employees 2 and fulltime employees 7, on average.

Table 2. Descriptive statistics

\begin{tabular}{|c|c|c|c|c|c|c|c|}
\hline $\begin{array}{l}\text { Continuous } \\
\text { variables }\end{array}$ & $N$ & Minimum & Махітит & Mean & $\begin{array}{c}\text { Std. } \\
\text { Deviation }\end{array}$ & Skewness & Kurtosis \\
\hline$O M$ & 429 & -10.00 & 24.29 & .3691 & 1.50561 & 11.279 & 180.718 \\
\hline CUSSEL & 626 & 0.00 & 100.00 & 31.5040 & 41.31723 & 0.776 & -1.203 \\
\hline CUSAGR & 612 & 0.00 & 100.00 & 64.5267 & 44.11844 & -0.608 & -1.512 \\
\hline$B I G C U S$ & 579 & 0 & 100 & 47.10 & 30.881 & 0.356 & -1.156 \\
\hline MANOWN & 478 & 0 & 100 & 78.10 & 26.716 & -0.609 & -1.161 \\
\hline$M A N A G E$ & 630 & 1936 & 1984 & 1961.06 & 8.587 & 0.355 & -0.485 \\
\hline EMFUL & 570 & 0.00 & 300.00 & 7.3289 & 16.44788 & 11.153 & 180.702 \\
\hline EMPAR & 435 & 0.00 & 100.00 & 2.0920 & 5.81073 & 12.504 & 194.572 \\
\hline EMTOT & 392 & 0 & 400 & 9.11 & 23.632 & 12.474 & 195.885 \\
\hline SALES & 535 & 1.40 & 150000.00 & 1000.25 & 7812.22 & 16.876 & 296.436 \\
\hline ASSETS & 243 & -100.00 & 20000.00 & 396.41 & 1369.35 & 12,395 & 175.251 \\
\hline $\begin{array}{l}\text { Discrete } \\
\text { variables }\end{array}$ & $N$ & Minimum & Махітит & Mean & $\begin{array}{c}\text { Std. } \\
\text { Deviation }\end{array}$ & Skewness & Kurtosis \\
\hline GRDES & 667 & 1 & 4 & 2.675 & .756 & -.052 & -.381 \\
\hline COMINV & 651 & 1 & 5 & 2.72 & 1.276 & .353 & -.940 \\
\hline СООРОT & 664 & 1 & 5 & 2,52 & .927 & .478 & -.198 \\
\hline GENDER & 665 & 1 & 2 & $1.19(81 \%)$ & 0.3962 & 1.551 & .408 \\
\hline MANED & 664 & 1 & 5 & 2.83 & .738 & .060 & 1.248 \\
\hline
\end{tabular}

\section{Model fit}

The assumptions of the linear regression analysis have been taken into account in this paper. First, the linearity of dependent and independent variables has pretested with the t-test and these results encouraged us to continue with the customer concentration variables into multiple regression. The same idea we get from the Pearson correlation analysis table where we can see some significant correlations between dependent and independent variables. (Table 3). The independency of observations was substantiated by Durbin-Watson test as value being 0.801 (reference values are 0-4). Also, the outliners of the observations were checked and removed, as well as the normality of the variables has tested. The normality of the variables is presented in the descriptive statistics table and as we can see, the skewness and kurtosis of all the independent variables applied in linear regression analysis are near one (table 2). The collinearity of the model was tested along the linear regression analysis in the 
collinearity column. The correlation table of all the variables doesn't shows any correlations above 0.3 between two independent variables. This meaning, no harmful correlations exist. As all the tolerance figures are above 0.02 and VIF-figures are under five, the results show us that no harmful multi-collinearity exists.

Table 3. Pearson correlation table

\begin{tabular}{|c|c|c|c|c|c|c|c|c|c|c|c|}
\hline & OM & BIGCUS & CUSAGR & CUSSEL & GRDES & COMINV & COOPOT & MANAGE & GENDER & MANED & EMPTOT \\
\hline OM & 1.000 & $-.185^{* *}$ & $-0.315^{* *}$ & $0.322 * *$ & $0.128 * *$ & 0.082 & $-0.095 *$ & $-0.105^{*}$ & $-0.134 * *$ & $-0.191 * *$ & $-0.193 * *$ \\
\hline BIGCUS & 0.034 & 1.000 & $0.414 * *$ & $-0.443^{* *}$ & 0.052 & -0.023 & $0.101 *$ & -0.059 & 0.050 & 0.080 & -0.035 \\
\hline CUSAGR & -0.041 & $.443 * *$ & 1.000 & $-.912 * *$ & -0.037 & -0.021 & $.212 * *$ & 0.045 & $.210^{* *}$ & $.223 * *$ & $0.185^{* * *}$ \\
\hline CUSSEL & 0.043 & $-.467 * *$ & $-.912 * *$ & 1.000 & 0.018 & -0.004 & $-.232 * *$ & $-.088 *$ & $-.221 * *$ & $-.247 * *$ & $-0.181 * *$ \\
\hline GRDES & 0.018 & 0.033 & -0.037 & 0.075 & 1.000 & $.261 * *$ & $-.138 * *$ & $-.207 * *$ & -0.026 & -0.047 & $-0.166^{* * *}$ \\
\hline COMINV & 0.021 & -0.022 & -0.021 & 0.011 & $.258 * *$ & 1.000 & $-.154 * *$ & $.079 *$ & -0.072 & -0.077 & $-0.125^{*}$ \\
\hline COOPOT & -0.048 & 0.078 & $.212 * *$ & $-.220 * *$ & $-.135 * *$ & $-.146 * *$ & 1.000 & 0.078 & $.084 *$ & $.124 * *$ & 0.046 \\
\hline MANAGE & -0.046 & -0.066 & 0.045 & $-.093^{*}$ & $-.210 * *$ & 0.063 & $.083 *$ & 1,000 & 0.063 & 0.050 & $0.154^{* * *}$ \\
\hline GENDER & -0.091 & 0.044 & $.210 * *$ & $-.193 * *$ & -0.013 & -0.071 & $.078 *$ & 0.059 & 1.000 & $.163 * *$ & 0.052 \\
\hline MANED & 0.031 & 0.053 & $.223 * *$ & $-.213 * *$ & -0.039 & -0.070 & $.103^{* *}$ & 0.025 & $.148 * *$ & 1.000 & 1.000 \\
\hline EMPTOT & $-.193 * *$ & -0.035 & $0.185^{* *}$ & $-0.181 * *$ & $0.166^{* *}$ & $-0.125 *$ & 0.046 & $0.154 * *$ & 0.052 & 1.000 & 1.000 \\
\hline
\end{tabular}

\section{Customer concentration and firm performance}

The multiple linear regression model for examining the effects of the customer concentration on the firm's profitability is as follows.

OM $=\beta_{0}+\beta_{1}$ BIGCUS/CUSARG/CUSSEL $+\beta_{2}$ GRDES $+\beta_{3}$ COMINV $+\beta_{4}$ COOPOT + $\beta_{5} M A N A G E L N+\beta_{6} G E N D E R+\beta_{7} M A N E D+\beta_{8}$ EMPTOT $+\varepsilon$

As the dependent variable, we apply the firm's profitability $(\mathrm{OM})$ defined as EBIT to the turnover of the year. Most of the previous studies indicate that there is a negative connection between customer concentration and the performance of a company (Balakrishnan et al. 1996; Cosman and Kohlbeck 2009; Kelly and Gosman; 2000 Snyder 1998). Our first measure is the state of the firm's main customer (BIGCUS). However, also defensive literature exists for the positive influence of the customer concentration on a firm's performance (Galbraith and Stiles 1983; Gosman's et al. 2004; Kohlbeck 2011; Pfeffer and Salancik 1978: Dill 1981). Furthermore, there are studies where they could identify both positive and negative effects, depending on company's age (Irvine et al. 2016) and the ratio of the firm's performance (Patatoukas 2012). These diversified results can be explained for example by size, age or industry of the company.

In Table 4 we represent the multiple linear regression results. It uses operating margin as dependent variable and analyze it with customer based variables and several control variables as independent variables. Operating variable measuring here the profitability of the company. The customer effects are measured as percentages of the customer concentration or firm's customer engagement methods. 
Table 4: Multiple regression analysis

\begin{tabular}{|l|r|r|r|r|r|r|}
\cline { 2 - 7 } \multicolumn{1}{c|}{} & \multicolumn{2}{c|}{ BIGCUS as dependent } & \multicolumn{2}{c|}{ CUSAGR as dependent } & \multicolumn{2}{c|}{ CUSSEL as dependent } \\
\cline { 2 - 7 } \multicolumn{1}{c|}{} & coefficient & \multicolumn{1}{c|}{$\boldsymbol{p}$-value } & coefficient & p-value & coefficient & \multicolumn{1}{c|}{ p-value } \\
\hline (Constant) & 4.113 & 0.398 & 3.952 & 0.404 & 3.780 & 0.412 \\
\hline BIGCUS & -.002 &, 022 & & & & \\
\hline CUSAGR & & & -.002 & .000 & & \\
\hline CUSSEL & & & & & .002 & .000 \\
\hline GRDES & .051 &, 095 & .054 & .066 & .050 & .081 \\
\hline COMINV & .027 &, 116 & .020 & .226 & .029 & .072 \\
\hline COOPOT & -.010 &, 670 & -.004 & .875 & -.003 & .892 \\
\hline MANAGE & -.002 &, 452 & -.002 & .457 & -.002 & .434 \\
\hline GENDER & -.072 &, 119 & -.035 & .441 & -.037 & .396 \\
\hline MANED & -.037 &, 271 & -.028 & .383 & -.019 & .557 \\
\hline EMPTOT & -.006 &, 000 & -.005 & .001 & -.005 & .001 \\
\hline N & 448 & & 444 & & 450 & \\
\hline Adjusted $\boldsymbol{R}^{2}$ & .157 & & .198 & & .209 & \\
\hline
\end{tabular}

Dependent Variable: OM

\section{Results}

Regression shows us a significant relationship of the performance of the company with customer concentration, as well as with the engagement methods. We arranged three mutual multivariate regression analyses. In all these three panels, the dependent variable was the performance of the firm, the operating margin figure. Also, the last six control variables were the same in all three analyses. Hence, only the first explanatory variable, the customer variable (BIGCUS, CUSSEL and CUSAGR) was changed. The BIGCUS illustrating the customer concentration had almost a significant negative effect, as did CUSARG of the purchase agreement variable on the operating margin figure as well. In opposite, the third customer variable, CUSSEL, the variable of self-paying customers, affected significantly positively on the company's performance.

Some of the control variables had a significant effect on the company's operating margin beside the customer variables. In the first two panels, the EMPTOT as the number of employees had significant negative influence and the GRDES as growth is desired had almost significant positive influence on $\mathrm{OM}$ with the respect of interaction of customer concentration (BIGCUS) in the model. In the second two panels the situation is the same, where we viewed the regression with customer agreement variable (CUSAGR) as explanatory variable. In the last two panels, with the customer self-paid variable (CUSSEL) as an explanatory variable, we can notice the same significant positive parallel influence of the EMPTOT and GRDES variables. The employee number effect negatively and the growth desire effect positively on the company's performance. Additionally, here with the CUSSEL as explanatory variable the COMINV as the investments into competition situation is almost significant variable for the profitability of the company (Table 4).

\section{Conclusions}

In this paper, we introduce one model to explain the company's customer base and the performance of the company together. It is obvious that the profitability is a combination of the diverse factors. Hence, we apply seven different variables amongst the customer variable in this study. These variables come from the health care survey, which was provided in 
Finland in 2010. This industry in Finland is especially sensitive to the customer concentration because the health care firms often offer their services to the municipalities which on one side give safe and reliable income but on the other hand, are powerful in price and contract negotiation.

We assumed in our hypothesis that the customer concentration may hamper firm's profitability by increasing the degree of the risk. We evident, that the customer concentration is one of the important factors in company's profitability. Our analysis shows significant relationship between company's profitability as the operating margin and the three customer variables. First, the variable for the one biggest customer shows negative effect. Also, the second customer variable, purchase of service agreement, effects negatively. Alternatively, the third variable which measures the self-paying customers, effects positively on company's profitability. These results telling us that the fewer customers companies and the more purchase agreements, the less profitable the health care companies are. In opposite, the more self-paying customer the better profitability the firm has.

There were also other, contingency theory based, factors alongside customer variables that showed significances in our analyses. One big customer and company's desire to grow increases the company's profitability while employee number decreases it. Totally, the same situation is with the second customer variable. In the case of the self-paying customer, the company's investment towards competition and company's desire to grow both effect positively on the operating margin of the company and the employee size of the company effects opposite. These results showing us that the company's investments in the competition are useful for the firm. The results can be biased because data is relatively small. However, this paper evident that in service, more precisely in health care private business and in relatively small companies, in this data, the customer consideration plays a role in decreasing company's profitability although according previous literature for instance in manufacturing business the results was opposite among big and older companies.

\section{References}

Bae, K., Wang, J. (2015). Why do firms in customer-supplier relationships hold more cash? International Review of Finance, no. 15 (4), pp. 489-520.

Balakrishnan, R., Linsmeier, T. J., Venkatachalam, M. (1996). Financial benefits from JIT adoption: Effects of customer concentration and cost structure. Accounting Review, no. 71 (2), pp. 183-205.

Banerjee, S., Dasgupta, S., Kim, Y. (2008). Buyer-supplier relationships and the stakeholder theory of capital structure. Journal of Finance 63 (5), pp. 2507-2552.

Banker, R. D., Byzalov, D., Plehn-Dujowich, J. M. (2014). Demand uncertainty and cost behavior. The Accounting Review, no. 89 (3), pp. 839-865.

Becchetti, 1. and J Sierra, J. (2003). Bankruptcy risk and productive efficiency in manufacturing firms. Journal of banking \& finance, no. 27 (11), pp. 2099-2120.

Campello, M. and Gao, J. (2014). Customer concentration and loan contract terms. papers.ssrn.com. Social Science Research Network. Retrieved July, 2016.

http://papers.ssrn.com/sol3/papers.cfm?abstract_id=2442314.

Casciaro, T., and M. J. Piskorski. (2005). Power imbalance, mutual dependence, and constraint absorption: A closer look at resource dependence theory. Administrative Science Quarterly, no. 50 (2), pp. 167-199. 
Contractor, F. J., Kundu, S. K. and Hsu, C. C. (2003). A three-stage theory of international expansion: the link between multinationality and performance in the service sector. Journal of International Business Studies, no. 34, pp. 5-18.

Galbraith, C. S. and Stiles, C. H. (1983). Firm profitability and relative firm power. Strategic Management Journal, no. 4, pp. 237-249.

Gosman, M. L., Kohlbeck, M. J. (2009). Effects of the existence and identity of major customers on supplier profitability: Is Wal-Mart different? Journal of Management Accounting Research no, 21, pp. 179-201.

Gosman, M., Kelly, T., Olsson, P., Warfield, T. (2004). The profitability and pricing of major customers. Review of Accounting Studies, no. 9 (1), pp. 117-139.

Gulati, R., Sytch, M. (2007). Dependence asymmetry and joint dependence in interorganizational relationships: Effects of embeddedness on a manufacturer's performance in procurement relationships. Administrative Science Quarterly no. 52 (1), pp. 32-69.

Huang, H. H., Lobo, G. J., Wang, C., Xie, H. (2014). Customer Concentration and Corporate Tax Avoidance. papers.ssrn.com. Redrieved July, 2016.

http://papers.ssrn.com/sol3/papers.cfm?abstract_id=2469859.n

Irvine, P., Park, S. S., Yildizhan, C. (2016). Customer-base concentration, profitability and relationship life cycle. The Accounting Review, no. 91 (3), 883-906.

Kelly, T., Gosman, M. L. (2000). Increased Buyer Concentration and Its Effects on Profitability in the Manufacturing Sector. Review of Industrial Organization, no. 17 (1), pp. 41-59.

Kinney, M. R., and Wempe, W. F. (2002). Further evidence on the extent and origins of JIT'S profitability effects. The Accounting Review, no. 77 (1), pp. 203-225.

Kohlbeck, M. (2011). Investor valuations of suppliers' major customer disclosures. Advances in Accounting, no. 2, pp. 278-285.

Patatoukas, P. N. (2012). Customer-Base Concentration: Implications for Firm Performance and Capital Markets. The Accounting, no. 87 (2), pp. 363-392.

Pfeffer, J., Salancik, G. R. (1978). The External Control of Organizations: A Resource Dependence Perspective. New York: Harper and Row. Reviewed by William R. Dill. 1981. American journal of Sociology, no. 87 (3), pp. 757-759.

Raman, K., Shahrur, H. (2008). Relationship-specific investments and earnings management: Evidence on corporate suppliers and customers. The Accounting Review, no. 83 (4), pp. 10411081.

Rissanen, S., Hujala, A., Helisten, M. (2010). The State and Future of Social Service Enterprises a Finnish Case. European Journal of Social Work, no. 13 (3), pp. 319-337.

Rissanen, S., Hujala, A., Laukkanen, V., Helisten, M., Taskinen, H. (2011). Start-up Motivations and Growth Orientation of Owners of Family Business - a Care Entrepreneurship Approach. Electronic Journal of Family Business Studies 5 (1-2), pp. 55-73.

Silva, A. P., Santos, C. M. (2011). Financial and strategic factors associated with the profitability and growth of SME in Portugal. International Journal of Economics and Finance. 3 (4), pp. 46-60.

Snyder, C. M. (1998). Why do larger buyers pay lower prices? Intense supplier competition. Economics Letters 58 (2), pp. 205-209. 